\title{
Experimental Study and Motion Simulation of Biomass Particles in Suspension Fluidized Unit
}

\author{
Zhaojun $^{1, a}$, Wangxi $^{2, b}$ and Zhuangweidong ${ }^{3, c}$ \\ 1,2,3Engineering College, Heilongjiang Bayi Agricultural University, Daqing163319,Chain \\ adqzhaojun@163.com, bndwangxi@163.com, '81nd@163.com
}

Keywords: Biomass,suspension,fluidization,fluidization characteristics.

\begin{abstract}
The research and application of biomass have been paid more and more attention. In this paper, a new experimental device is designed by oneself. The corn cob and rice husk are carried out separately on a separate and mixed flow of fluid. Using FLUENT software, the gas-solid movement of the particle was simulated by Euler two-fluid model and mixture pressure, particle concentration, particle velocity was simulated on the bed. The experimental study results show that biomass can be fluidized. The effect of fluidization of biomass particles is very poor, and a certain proportion of inert particles must be added to achieve a better fluidization effect.In the mixed fluidization of biomass and quartz sand, the mass fraction is $20 \sim 30 \%$, and the fluidization effect is good. When suspended fluidization enter into the stable transport state, the bed particle concentration is basically the same. In the central bed, fluidization effect is not satisfactory, it can improve the layout design of the wind board.
\end{abstract}

\section{Introduction}

Biomass energy is a kind of renewable energy. It is important to exploit and utilize biomass energy [1,2]. Energy shortage can be relieved, fossil fuels utilization can be reduced and energy construction can be modified in the future [3]. It is an important method of biomass energy development and research to transform biomass to high quality liquid fuels through fast pyrolysis of biomass technology $[4,5]$. Biomass pyrolysis and gasification is a very effective way of using energy and it can produce gas and synthesis gas [6].The suspension fluidized bed, which can be carried out in batch processing, has good performance of heat and mass transfer process and easy to control, is an important way of biomass pyrolysis and gasification [7].The suspension fluidized bed is considered to be solid particle fluid. When the fluid upwards through the accumulation of solid particle layer in the container, the particles loses contact with the particles [8]. The friction phenomenon between particles are eliminated. The purpose of solid particle fluid is achieved. In the fluidization process, uniform particles have full contact and reaction opportunities between particle and fluid. A heat and mass transfer in favor of particle material in the bed. The single biomass particles are not easy to flow because the characteristics of the biomass particles, such as irregular shape, rough surface, high water content and agglomerate easily. In the actual operation process, inert particles of quartz sand are joined in the bed to improve the fluidization quality and enhanced heat transfer process. The biomass particle and fluidizing gas are fully mixed to achieve rapid pyrolysis gasification purposes $[9,10]$.CLARKE studied biomass mixed flow with other biomass particles with different shapes, density, particle size. This study focused on the pressure drop, mixed situation and so on[11]. PRARISE studied the flow characteristics of two different density particles at different bed height and aspect ratio. Using the Gaussian spectral pressure distribution method, it was found that the fluidized quality was fine at low bed height, low aspect ratio and low particle density[12]. JAIBOON measured pressure pulsation at fluidized bed and circulating fluidized bed riser, analyzed the flow spectrum with different pressure pulsation signal, pointed out that the different flow patterns and riser height of the power spectral density showed a different distribution feature[13].The particle and chemistry characteristic of biomass raw material are not perfect. The biomass cooling fluidization test-bed is established. Corn cob and rice husk fluidization experiments are executed separately, then, the mixture fluidization experiments are executed [14]. And the bed gas-solid motion parameters is 
simulated, obtained the biomass fluidization basic law, provided the reference for the engineering application of biomass fast pyrolysis on fluidized bed.

\section{Experimental Device and Scheme}

The biomass raw material for experiment is corn cob and rice husk. Corn cob diameter is $40 \sim 60$ mesh, the average particle size is $315 \mu \mathrm{m}$ and the average density is $146 \mathrm{~kg} / \mathrm{m}^{3}$. Rice husk particle diameter is $40 \sim 60$ mesh, the average particle size is $315 \mu \mathrm{m}$, and the average density is $212 \mathrm{~kg} / \mathrm{m}^{3}$. Quartz sand particle diameter is $40 \sim 70$ mesh, the average particle size is $230 \mu \mathrm{m}$ and the average density is $1643 \mathrm{~kg} / \mathrm{m}^{3}$.

The experimental fluidizing gas is air and air density is $1.205 \mathrm{~kg} / \mathrm{m}^{3}$. The room temperature is $20^{\circ} \mathrm{C}$. The kinematic viscosity is $15 \times 10^{-6} \mathrm{~m}^{2} / \mathrm{s}$ and the dynamic viscosity is $18.08 \times 10^{-6} \mathrm{~Pa} \cdot \mathrm{s}$.

The experimental device comprises an air compressor, rotor flowmeter, cylindrical suspension bed, $\mathrm{U}$ type pressure gauge, as shown in figure 1 . Cylindrical suspension bed is made of organic glass. The inner diameter is $100 \mathrm{~mm}$ and the height is $1000 \mathrm{~mm}$. The side of the bed is a gauge to read a biomass height of the bed. The bottom bed and the upper bed is provided with a hole. The hole connected with a $U$ tube manometer. It is used to measure the different height of the bed pressure. The fluidized medium is provided by an air compressor in experimental process. The bottom bed is air distribution holes with uniform distribution. The compressed air through distribution holes to the fluidized bed. The bed material could be in fluidization by the air. The bed flow and pressure can be read in the rotor flow meter and $U$ type pressure gauge. $U$ type pressure gauge end is connected with air chamber, the other end is connected with upper air distribution holes [15,16].

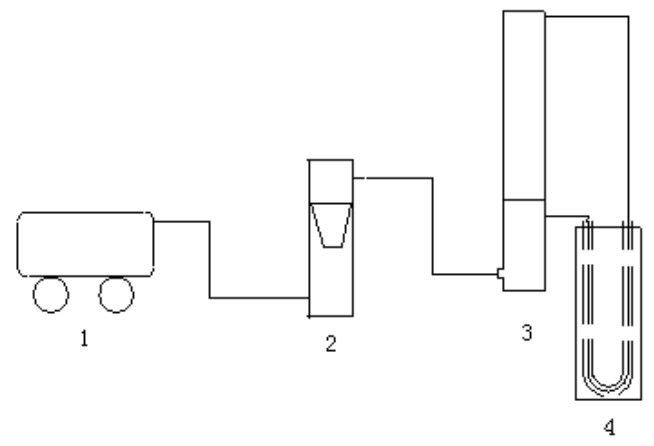

Figure 1 The sketch map of experimental unit

1.Air compressor 2.Rotor flowmeter 3.Cylindrical suspension bed 4.U type pressure gauge

\section{Experimental results and analysis}

\subsection{Experimental study on the fluidization of single biomass}

At first, the corn cob fluidization experiment is studied [17]. Observing the process of experiment, it shows: the flow of the wind speed is low, a small amount of corn cob on the upper bed is fluidized, other corn cob did not move. With the increase of flow velocity, the amount of corn cob fluidization increased. the corn cob also began to move at the bottom bed, but the traveling speed is slow. With fluidization velocity continues to increase, the corn cob at bottom bed can be moved fast. The amount of fluidization of the corn cob layer on top bed increased significantly.

The pressure signal includes the comprehensive factors in the bed, including bubble generation, flow, coalescence and fracture, and particle disturbance, which is the external dynamic reflection of bed flow.The changing curve of bed pressure with the bed height at different fluidization velocity, the height of corn cob material are respectively $1 \mathrm{D}$ (D is the bed diameter) and $1.4 \mathrm{D}$, as shown in figure 2.The figure shows that the pressure difference increases with the bed height increases. The bed pressure remained unchanged until the bed layer reaches a certain height. These legends indicate the differential pressure of dense phase particles on the bottom bed remains less change. The differential pressure of dilute phase on top bed changes in the larger and particles be in the fluidized state [18]. 
When the fluidization wind velocity changed, each measuring point pressure was little changed. This process has not definite regularity. When the height of bed layer is high(1.4D), the differential pressure of bed has small change. Therefore, fluidization velocity on bed has little effect on pressure. Therefore, the fluidized air velocity has little effect on the pressure difference in the bed. Fig.3 shows the curve of different pressure of rice husk with bed height under different fluidizing wind speeds.

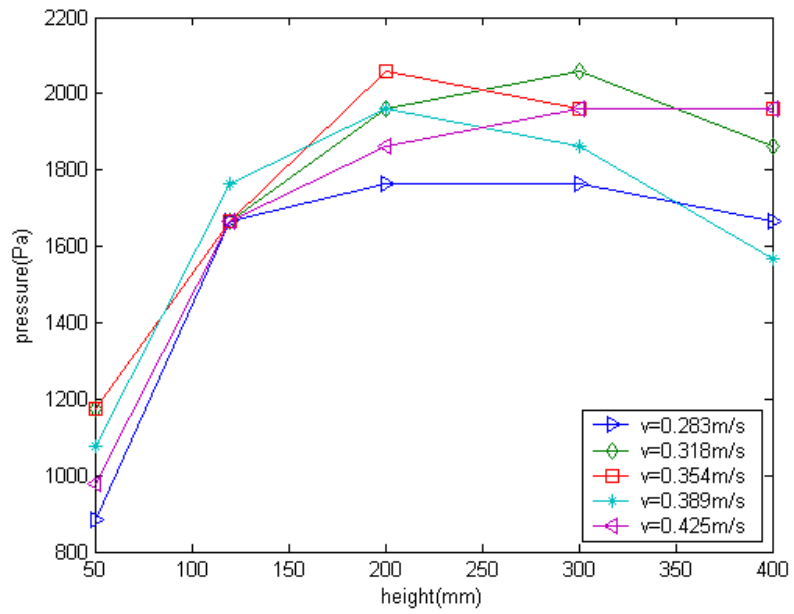

(a)

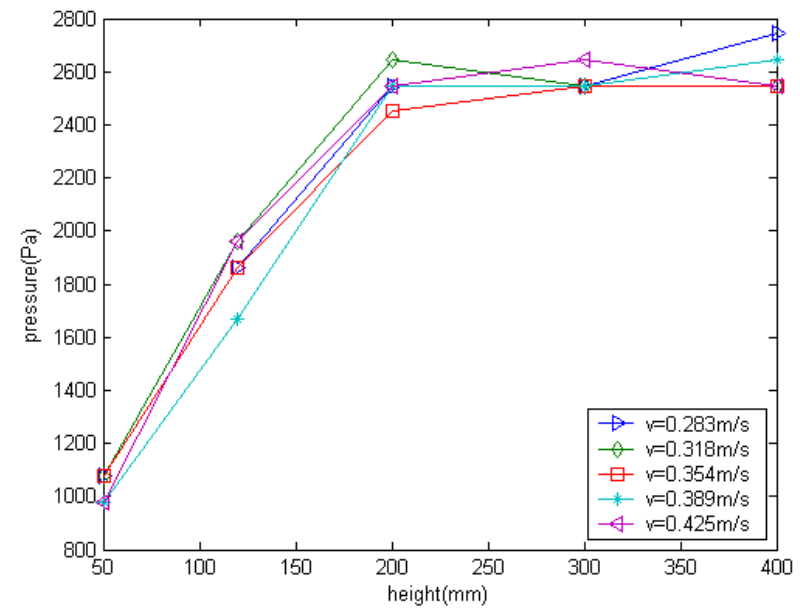

(b)

Figure 2 The pressure with height at different fluidized wind speed on corn cob

(a) $\mathrm{H}=1 \mathrm{D}$ (b) $\mathrm{H}=1.4 \mathrm{D}$

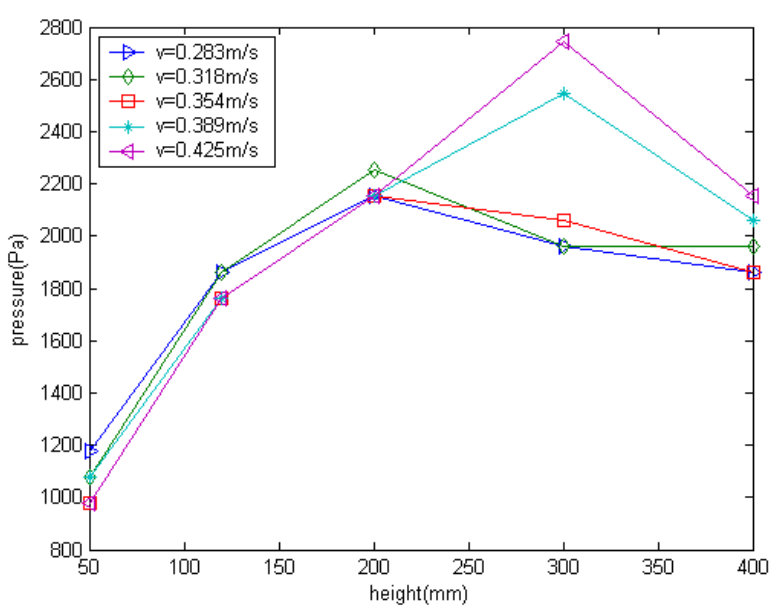

(a)

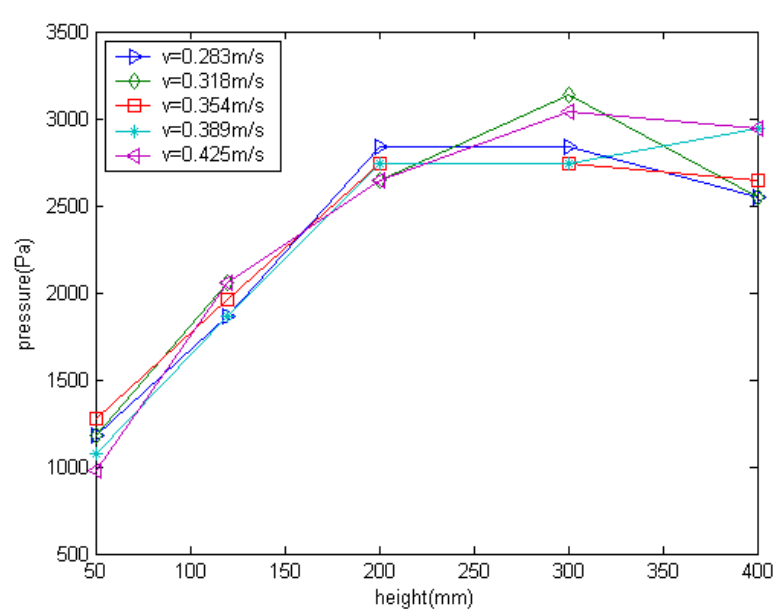

(b)

Figure 3 The pressure with height at different fluidized wind speed on rice husk

$$
\text { (a) } \mathrm{H}=1 \mathrm{D} \text { （b ) } \mathrm{H}=1.4 \mathrm{D}
$$

Figure 4 shows under the same fluidization velocity $(\mathrm{v}=0.425 \mathrm{~m} / \mathrm{s})$, corn cob layer height is different. The pressure changes with the bed height. From the diagram, the pressure increases with the material quantity. When the fluidization velocity remained consistent, corn cob quantity increases, particles fluidized drag increases and pressure increases too.It was found that the single biomass of corn or rice husk were not fluidized, due to the lighter particles and the larger interspace.

\subsection{Experimental study of the biomass mixed fluidization}

Due to irregular shape, small bulk density and poor liquidity, the biomass particles such as sawdust, straw, corn cob, rice husk, are not easy to achieve the ideal fluidization state [19]. When quartz sand, calcined limestone, olivine and other inert heavy raw material are fully mixed with biomass, these mixing material has also been good for the biomass particles. Because these heavy materials has large density and regular shape. 


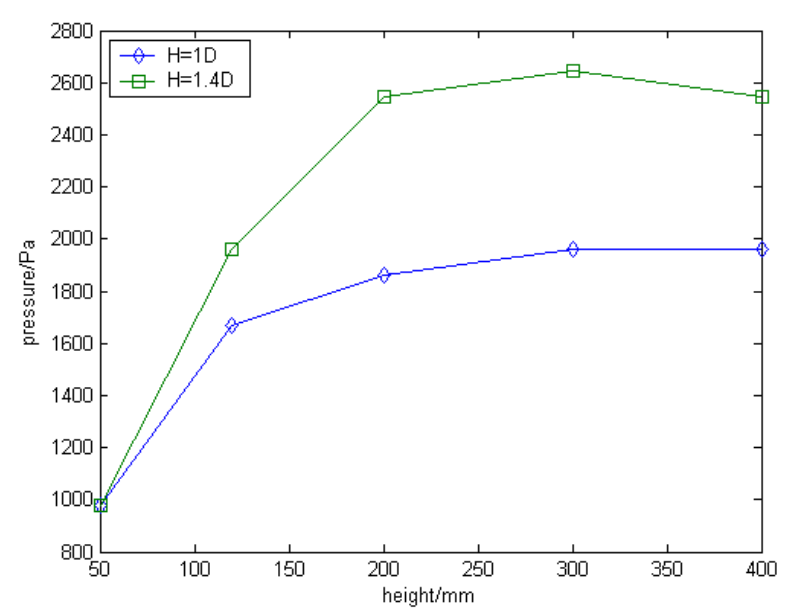

(a)

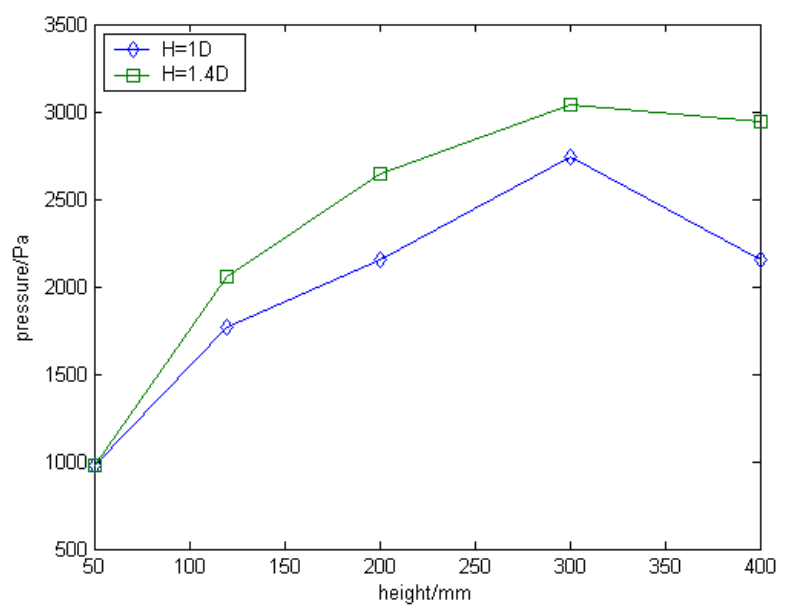

(b)

Figure 4 The pressure with height at same fluidized wind speed in different layers
(a) corn cob
(b) rice husk

The experiment using corn cob and rice husk and quartz sand mixed with biomass, mass fraction were $20 \%$ and $30 \%$, get the fluidization curve as shown in Figure 5 and figure 6 . The fluid curve can be shown,with the change of gas velocity, the average pressure difference of different biomass content showed a relatively stable overall trend after rapid increase, but, with the increase of biomass, the mean pressure difference did not change obviously. When the mass fraction of biomass increases, the average pressure drop has a downward trend.The main reason is that the density of biomass is much lower than that of quartz sand. With the increase of the biomass fraction, the biomass particles increase obviously, the average bulk density decreases obviously, the resistance of gas flowing through the bed decreases, the average pressure difference naturally decreases.

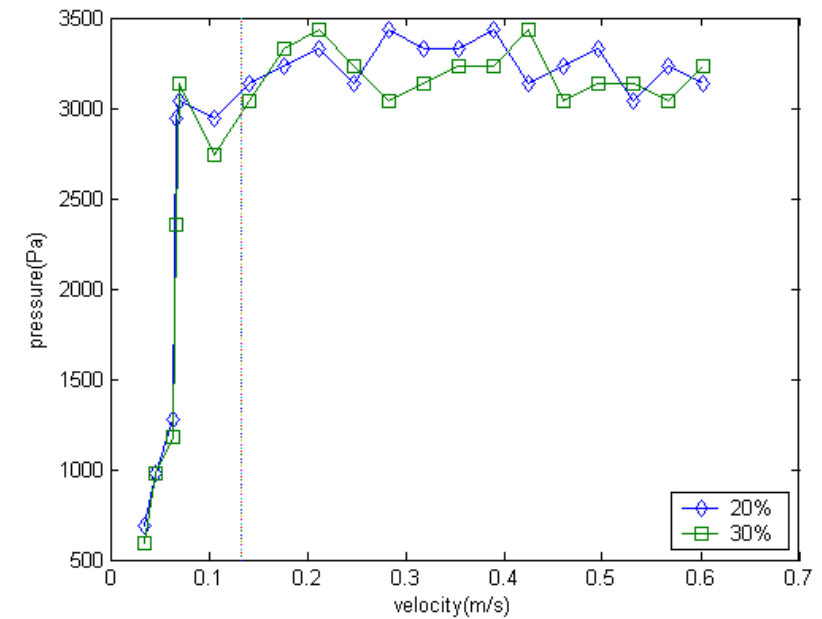

Figure 5 Mixing fluidization curves of corn cob and sand

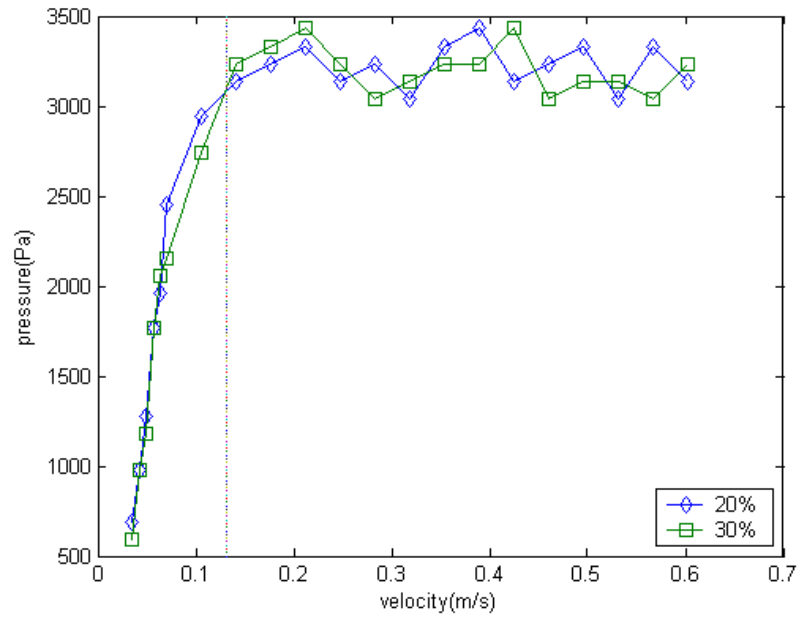

Figure 6 Mixing fluidization curves of rice husk and sand

\subsection{Simulation of biomass mixed fluidization}

FLUENT software is a computer program that is applied to a complex geometry modeling of fluid flow and heat transfer [20]. Through a menu driven interactive, friendly interface, to solve the problem and achieve results. Simulation conditions for two-phase flow in non steady state, select the EULERIAN two fluid model, the numerical method is the finite volume method, the turbulence model is the standard $\mathrm{k}-\varepsilon$ turbulence model, the fluid pressure velocity coupling based on SIMPLE algorithm. The initial particle velocity is set to $0 \mathrm{~m} / \mathrm{s}$. The particle is sand. The size is $0.23 \mathrm{~mm}$. The particle density is $1650 \mathrm{~kg} / \mathrm{m}^{3}$. The static bed height is $0.30 \mathrm{~m}$. The gas velocity is $1.27 \times 10^{-5} \mathrm{~N} . \mathrm{s} / \mathrm{m}^{2}$. During the simulation, the air distributor fluidized velocity is constant and air distribution is uniform. 
As shown in Fig. 7, the solid-phase particle concentration distribution, it can be seen from the stationary to the fluidized expansion of the bed until the final macroscopic motion of the fluidization process. At the beginning, the lower part of the bed is the solid particles, its concentration is high. the upper part of bed is air, its solid volume fraction is 0 . The particles begin to collect at the bottom of the bed under the action of gravity, and the particles in the middle of the bed are gathered together by airflow so the volume fraction is larger, as shown in Fig. 7 (a). As time passed, the bed thickness became higher and higher, and the portion where the concentration of the deposited particles shifted upward, as shown in Fig. 7 (b).The longer the fluidization time, the larger the concentration of particles are dispersed by the airflow, making the particles spread out along the inner wall, bed particle concentration tends to be consistent, as shown in Figure 7 (c). In the high-speed air flow, the particles flow along the pipe wall, when a certain time, the flow state has no significant change, as shown in Figure 7 (d). It can be considered to enter a stable fluidized state. The fluidization state of the area around the bed surface is good, and the particle concentration tends to be consistent. The central particle concentration in the bed is large, so the holes in the middle part of the air distribution plate are beneficial to the fluidization of particles.
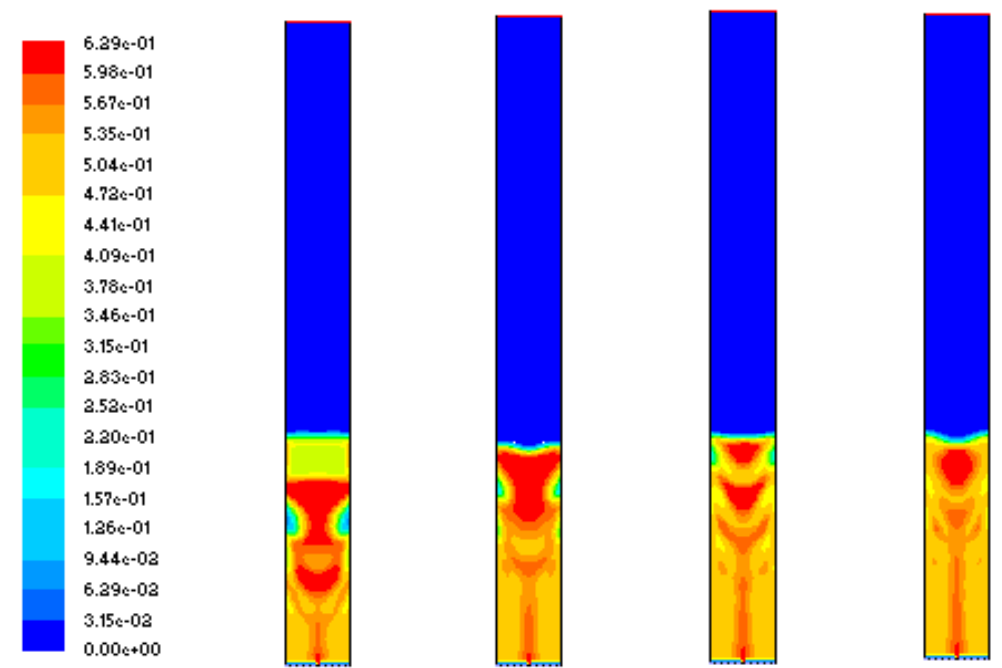
(a) $\mathrm{t}=1.0 \mathrm{~s}$
(b) $\mathrm{t}=1.4 \mathrm{~s}$
(c) $\mathrm{t}=1.8 \mathrm{~s}$
(d) $t=2.0 \mathrm{~s}$

Figure7 Particles concentration at different time

\section{Conclusions}

(1) The fluidization effect of single biomass is not satisfaction, the fluidization time is short, and a certain proportion of inert particles (such as quartz sand) must be added in order to achieve better fluidization effect.

(2) In the two-component mixed system of biomass and quartz sand, the biomass is corncob and rice husk, the kind of biomass has almost no influence to the fluidization quality of bi-mixture. The mass fraction is $20 \%$ and $30 \%$, the bi-mixture can be fluidized well. The proportion of quartz sand in the mixed system is important.

(3) Suspended fluidization simulation showed that there will be a larger particle concentration pulsation at the initial delivery of particles. When the fluidization entering the stable transport state, the bed particle concentration is basically the same. In the central bed, fluidization effect is not satisfactory, it can improve the layout design of the wind board.

\section{Acknowledgments}

This research was financially supported by the National Support Program and Dr. Fund Project. 


\section{References}

[1]Wuchuangzhi, Malonglong,The modern applied technology of biomass,Chemical Industry Press, Beijing, 2003.

[2]Y.Lin,S.Tanaka, Ethanol fermentation from biomass resources:current state and prospects. Appl Microbiol Biotechnol, New York, Springer-Verlag, 2005.

[3]Liao Cuiping, Yanyongjie, Wuchuangzhi, Huanghaitao, Study on the distribution and quantity of biomass residues resource in China. Biomass and Bioenergy, 27(2004)111-117.

[4]Morris K W, Fast pyrolysis of the bagasse to produce bio-oil fuel for power generation[J].Intermational Sugar Journal. 103(2007)259-263.

[5] Samy S .Sadaka .Two phase biomass air-steam gasification model for fluidized bed reactor, Biomass and bioenergy, 22(2002)439-487.

[6]Zhuxifeng, The principle and technology of biomass pyrolysis, University of Science and Technology of China Press, Hefei, 2006.

[7]Li Junfeng,Hu Runqing,Song Yanqina,etc, Assessment of sustainable energy potential of non-plantation biomass resources in China. Biomass and Bioenergy 29 (2005) 167-177.

[8]Heguangxiang,Yangsuohe,Jinhaibo,Research progress of flow and mass transfer behavior of bubbling bed reactor,Chemical industry and Engineering,24-1(2007)76-81.

[9] Di Blasi C.Kinetics and modeling of biomass pyrolysis. In:Bridgwater AV, editor. Fast pyrolysis of biomass: a handbook,vol.3. Newbury, UK:CPL Press;2005. p.121-46.

[10] Gorton WC, Knight JA (1984) cited by Di Blasi C. Kinetics and modeling of biomass pyrolysis. In: Bridgwater AV, editor. Fast pyrolysis of biomass: a handbook, vol. 3. Newbury: CPL Press; 2005.121-46.

[11] CLARKE K L, PUGSLEY T, HILL G Fluidization of moist sawdust in binary particle systems in a gas-solid fluidized bed[J]. Chemical Engineering Science, 2005, 60(24): 6909-6918.

[12] PRARISE M R, KURKA P R q TARANTO O P. The Gaussian spectral pressure distribution applied to a fluidized bed[J].Chemical Engineering and Processing: Process Intensification,2009, 48(1): 120-125.

[13] JAIBOON O, CHALEMSEVSUWAN B, MEKASUT L, et al.Effect of flow pattern on power spectral density of pressure fluctuation in various fluidization regimes[J]. Powder Technology, 2013, 233(2): 215-226.

[14]Songxinchao,Wangzhifeng,Sundongkai,etc,Experimental study on characteristics of biomass and coal mixed particle flow,Coal conversion,28-1(2005)74-77.

[15]Wangliqun,Songxu,Zhouhaosheng,etc,Experiment of two-component particle fluidization characteristics,Journal of Jiangsu University (NATURAL SCIENCE

EDITION),28-3(2007)232-236.

[16]Wangjiawen,Liuronghou,Two groups of fluidization characteristics analysis of biomass and quartz sand mixture composition, Agricultural Mechanization Research,11(2006)190-193.

[17]Jinyong,Zhujingxu,Wangzhanwen,Fluidization engineering principles,Tsinghua University press,Beijing,2001,17-37.

[18]Yangtaiyang,Wanganren,Zhangsuojiang,etc,Numerical simulation for fluid dynamics in a gas-solid bubbling fluidized bed,Computers and Applied Chemistry,22-3(2005)207-211.

[19] Van de Velden M, Baeyens J, Seville JPK, Fan X. The solids flow in the riser of a circulating fluidized bed viewed by positron emission particle tracking. Powder Technology 2007, in press,doi:10.1016/j.powtec.2007.07.027.

[20]Wangfujun,Computational fluid dynamics analysis,Tsinghua University press,2004. 